\title{
FESTO PNEUMATIC SERVO SYSTEM
}

\author{
Dr. Ichiro Temmyo, Michio SHIKANO and Toshiyuki Nishimura
}

\author{
FESTOK.K. \\ 1-26-10 Hayabuchi, Tsuzukiku \\ Yokohama Japan 224 \\ TEL: 045-593-5610FAX: 045-593-5678
}

\begin{abstract}
Pneumatic Servo System has been studied and developed in Europe in the latter half of ' 80 's by the great progress of micro electronics and the development of control software. At the same time, we (FESTO), one of the most biggest pneumatic manufacturers in the world, started to supply Pneumatic Servo System which can keep appropriate positioning accuracy, be operated rather easily and be supplied to the market with reasonable prices, and the no. of applications reached over thousand axes.

FESTO Pneumatic Servo System was introduced to the Japanese market in the beginning of 1994. Currently, it is used in the automobile industry, metal working machine, electric machine, handling machine, wood working machine, chemical machine, construction machine, packaging machine, food processing machine, and robot, etc.

The outline of FESTO Pneumatic Servo System, the examples of measurement results of control signals and the response comparison with the case driven with the normal solenoid valve are introduced here.
\end{abstract}

\section{AN OUTLINE OF PNEUMATIC SERVO SYSTEM}

By using FESTO Pneumatic Servo System, it is possible to have pneumatic actuators positioned at will in the middle with high accuracy, to control acceleration and deceleration to ease shock at the time of stopping by high speed, to select a position in respond to input conditions, to program movements, and to control movements following up to analogue input signals, such as sine wave, trapezoid wave etc.

FESTO Pneumatic Servo System consists of servo controller(SPC100), servo valve (MPYE5), actuator(cylinders, rotary actuators or air motors) and position sensor. We also prepared the cylinders integrated sensor to save space. (Fig.1)

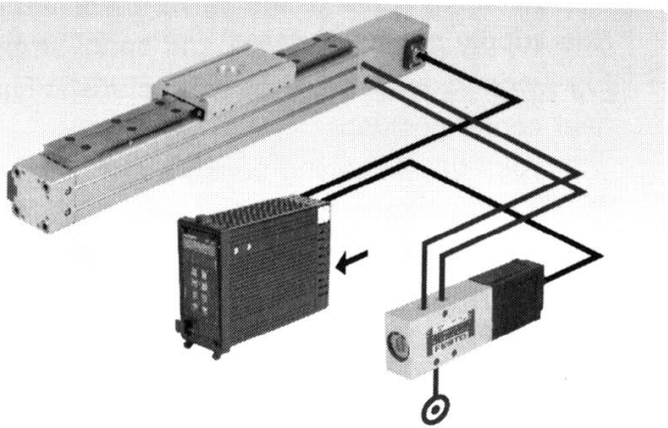

Fig. 1 FESTO Pneumatic Servo

Table 1

OUTLINE OF PNEUMATIC SERVO SYSTEM SPECIFICATION

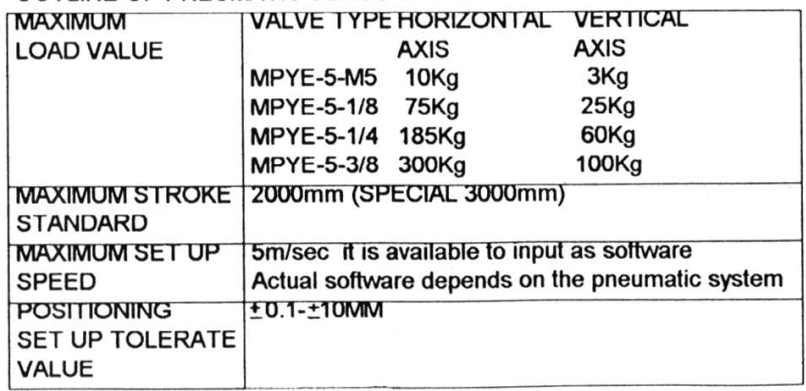


The outline of specification of FESTO Pneumatic Servo System is as shown in the Table 1. Where the load is relative bigger $(>3 \mathrm{~kg})$ and the stroke is relative longer $(>500 \mathrm{~mm})$, FESTO Pneumatic Servo System is more economical and fits for the relative higher speed applications $(>30 \mathrm{~mm} / \mathrm{s})$, and high response applications.

On comparison with electric servo system, the features of FESTO Pneumatic Servo System are high speed \& high response, and not to cause heat \& electric noise problem, space saving as driving motors are not mounted in actuators, and instead of servo driver, only servo valves is required which is compact and low cost. It means, FESTO Pneumatic Servo System is economical totally.

\section{AN OUTLINE OF PNEUMATIC SERVO SYSTEM COMPONENTS}

512 positions and 99 programs can be registered in the servo controller( Fig.1). NC program can be written by using $G$ code. If you input operation conditions such as loaded mass and diameter of pistons etc., the controller optimizes the control parameters automatically. In addition, it has also the functions of reading friction of the system and optimizing the dumping factor in each program steps. In regard to the operation mode, it is possible to select individual operation by servo controller (stand alone mode), parallel remote mode by PLC or PC, or serial remote mode.

Servo valve (Fig. 1 ) is $5 / 3$ center close spool type, driven with proportional solenoid. It possesses minor feed back function by means of the integrated spool position sensor. It has also the safety function to return to the center position automatically when the power supply is off. Fig.2 shows fflowrate/input voltage curve of the valve, and Fig. 3 shows frequency characteristic curve of the valve under the exciting conditions (the supply pressure: $1 \mathrm{Mpa}$ and spool stroke: $20-80 \%$ ). And Fig. 4 shows pressure gain characteristic curve of the valve at near center position.

2 types of positioning sensors are recommended to use for FESTO Pneumatic Servo System. One is low cost, contact type, analogue potentio meter. And the other one is non contact type, digital temposonic sensor which is long life and can be used under severe conditions as the protection degree is IP65.

\section{PNEUMATIC SERVO DRIVE SIGNAL MEASUREMENT EXAMPLE}

The slit tube type rodless cylinder, piston diameter $25 \mathrm{~mm}$ and stroke $500 \mathrm{~mm}$ with $3 \mathrm{~kg}$ mass, was driven by FESTO Pneumatic Servo System with 0.6 Mpa. Fig. 5 shows outline of the test.

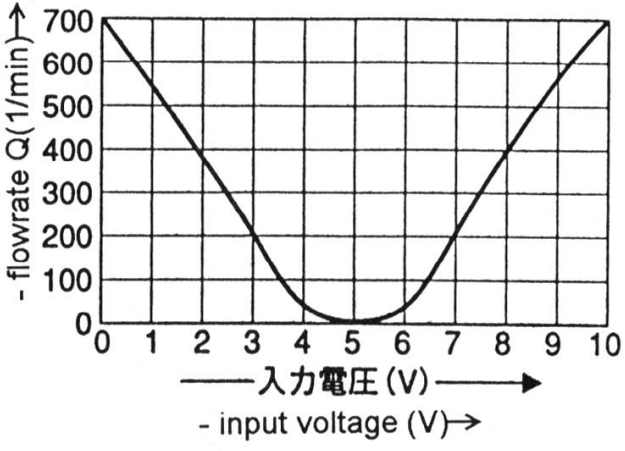

Fig 2 flowrate/input voltage

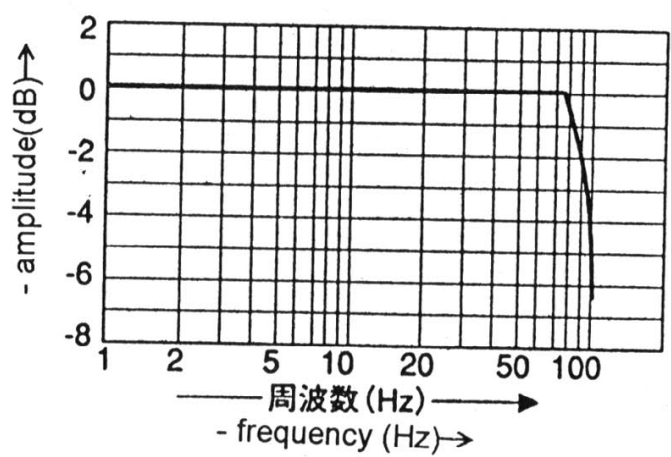

Fig 3 frequency characteristic curve

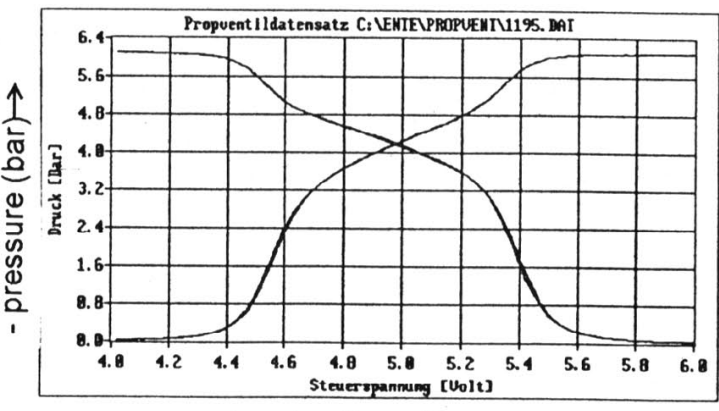

- input voltage $(V) \rightarrow$

Fig 4 pressure gain curve

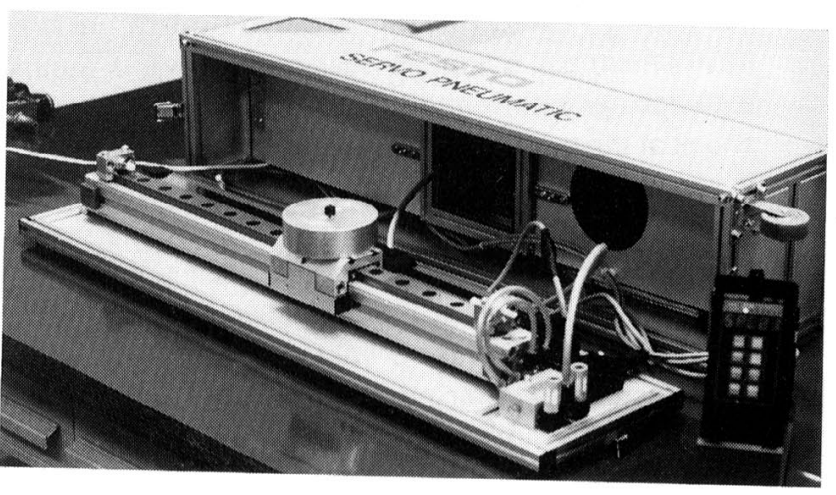

Fig 5 pneumatic servo system

used in measurement test 
Fig. 6 shows the case the axis is driven with the maximum acceleration from the position $50 \mathrm{~mm}$ to $250 \mathrm{~mm}$.

Driving program is

$$
\begin{array}{ll}
\text { GOO } & \times 50 \\
\text { GOO } & \times 250
\end{array}
$$

Line 1 indicates the set point position value, Line 2 the actual position value, Line 3 the control voltage $(0-10 \mathrm{~V})$ for the valve, Line 4 the actual value of pressure on the back side of the piston, and Line 5 the actual value of pressure on the front side of the piston.

At the same time when the program starts, control voltage $(10 \mathrm{~V})$ is added, and the valve full opens and max. speed reached to $2 \mathrm{~m} / \mathrm{s}$. However at $40 \%$ of the full stroke, the valve opens to opposite side, and the front side pressure of the piston reduced, during the back side pressure increased. Then axis is braked and can stop smoothly without overshoot.

Fig. 7 shows the case the axis is driven with a certain max.speed $1.5 \mathrm{~m} / \mathrm{s}$.

$$
\begin{array}{lll}
\text { G01 X50 } & F 10(=1.5 \mathrm{~m} / \mathrm{s}) \\
\text { G01 X250 } & \mathrm{F} 10
\end{array}
$$

At the same time when the program starts, the front side pressure increased once, but the valve decreases this pressure gradually to control to set value of max. speed, and at $70 \%$ of the full stroke, the valve opens to opposite side (reverses), and brakes the axis.

Fig. 8 shows the case the axis is driven with a certain acceleration and deceleration $1 \mathrm{~m} / \mathrm{s} 2$.

$$
\begin{array}{crc}
\text { G08 } & \text { X1(=1m/s2) } \\
\text { G09 } & \text { X1 } & \\
\text { G01 } & \text { X50 } & \text { F10 } \\
\text { G01 } & \text { X250 } & \text { F10 }
\end{array}
$$

This case shows the valve reverses often and controls to keep the set acceleration and deceleration values.

\section{COMPARISON ON RESPONSES OF THE DRIVE WITH NORMAL SOLENOID VALVES}

We compare responses at starting cylinders, which was used in test of article 4, of the case driven with the servo valve, with the case driven with the single solenoid $5 / 2$ valve. Now we know the step responses of the valve itself is $5 \mathrm{~ms}$ by the servo valve and $10 \mathrm{~ms}$ by the single solenoid $5 / 2$ valve.

Fig. 9 shows the measurement result with the servo valve. The details of the each line are the same as explained in the paragraph 4, but the driven stroke was changed to from 50 to $450 \mathrm{~mm}$ to keep nearly the same condition by the single solenoid $5 / 2$ valve, which drives $500 \mathrm{~mm}$ full stroke. Just before starting at the position $50 \mathrm{~mm}$, the pressure on both side of the piston are balanced at about $0.4 \mathrm{Mpa}$, that is also presumed from Fig.4. At the same time when the program starts, the control voltage of the servo valve increased from the center

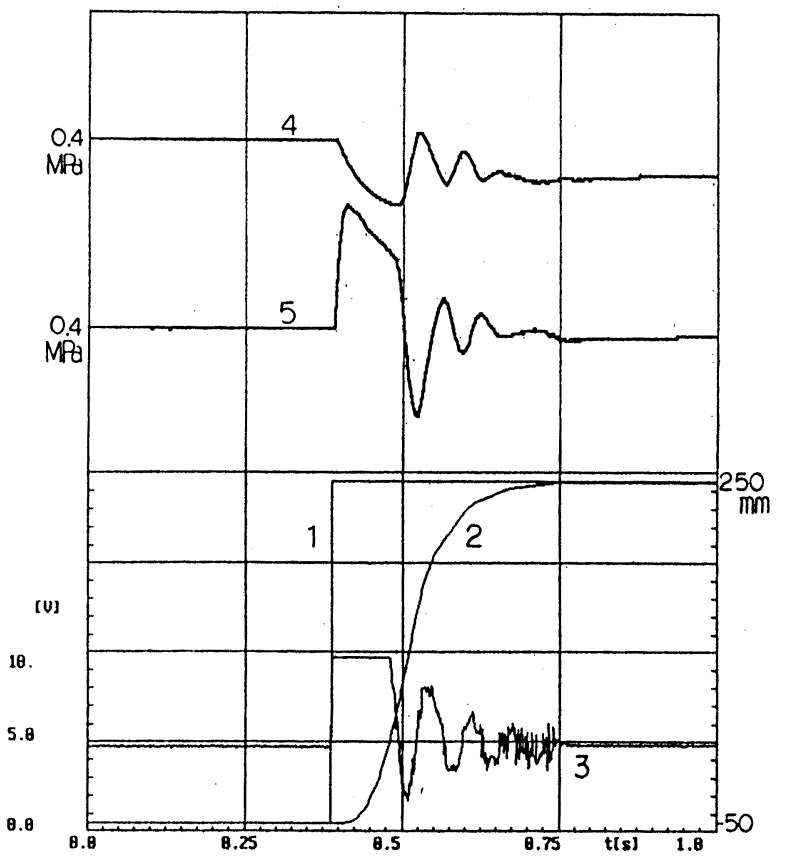

Fig 6 driven with max acceleration

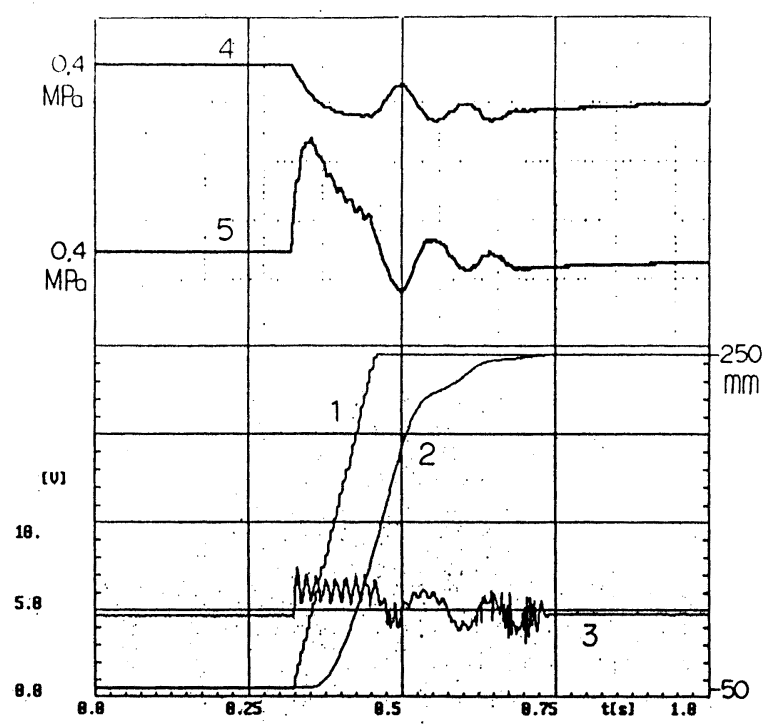

Fig 7 driven with a certain max speed $1.5 \mathrm{~m} / \mathrm{s}$

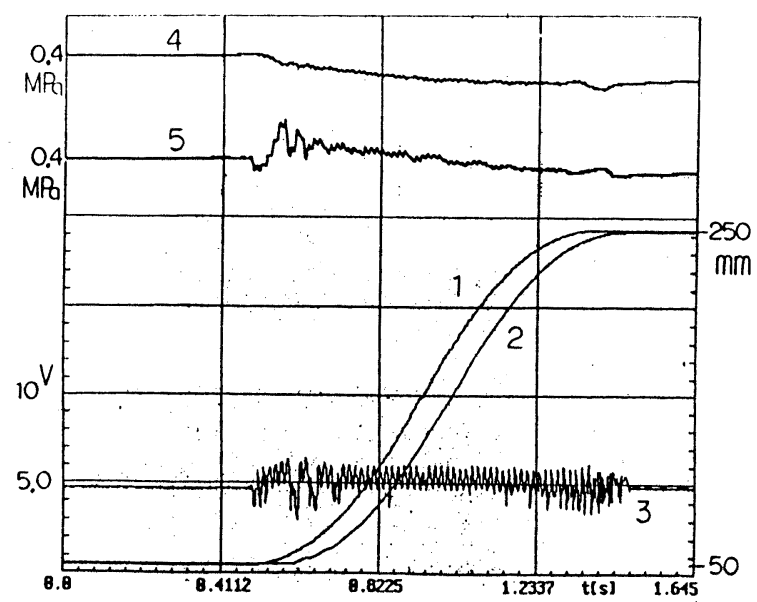

Fig 8 driven with a certain

acceleration \& deceleration $1 \mathrm{~m} / \mathrm{s}^{2}$ 
close middle point $5 \mathrm{~V}$ to $10 \mathrm{~V}$. Then the servo valve full opens, the pressure on front side of the piston increased from 0.4 to $0.6 \mathrm{Mpa}$, during the pressure on back side decreased from $0.4 \mathrm{Mpa}$, and the axis starts after around $25 \mathrm{~ms}$.

Fig. 10 shows the measurement result with the single solenoid $5 / 2$ valve. Line 1 indicates the actual position value, Line 2 the drive signal 24VDC for valve, Line 3 the actual pressure on back side of the piston, and Line 4 the actual pressure on front side of the piston. The axis starts after around $90 \mathrm{~ms}$ since the drive signal $24 \mathrm{VDC}$ is excited.

The reasons why the response with the single solenoid $5 / 2$ valve is longer, are the longer valve self response and the longer time required during the supplying pressure from 0 to $0.6 \mathrm{Mpa}$ to the front side of the piston and the exhausting pressure from $0.6 \mathrm{Mpa}$ from the back side compared to the case driven with servo valve.

\section{CONCLUSION}

The outlines of FESTO Pneumatic Servo System are introduced. The signals during servo drives as control signal to servo valve, the pressure in cylinder chambers, and the piston position signal are measured. The responses between the cases driven with servo valve and the normal single solenoid $5 / 2$ valve are compared. We wish increase of applications of Servo Pneumatics with understanding of its features.

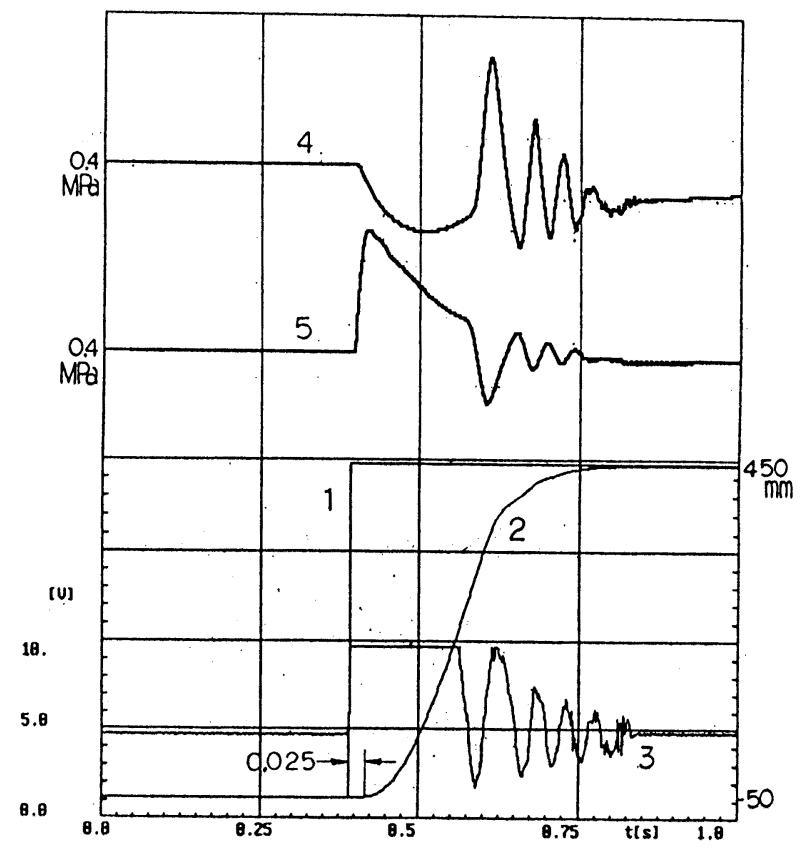

Fig 9 driven with servo valve

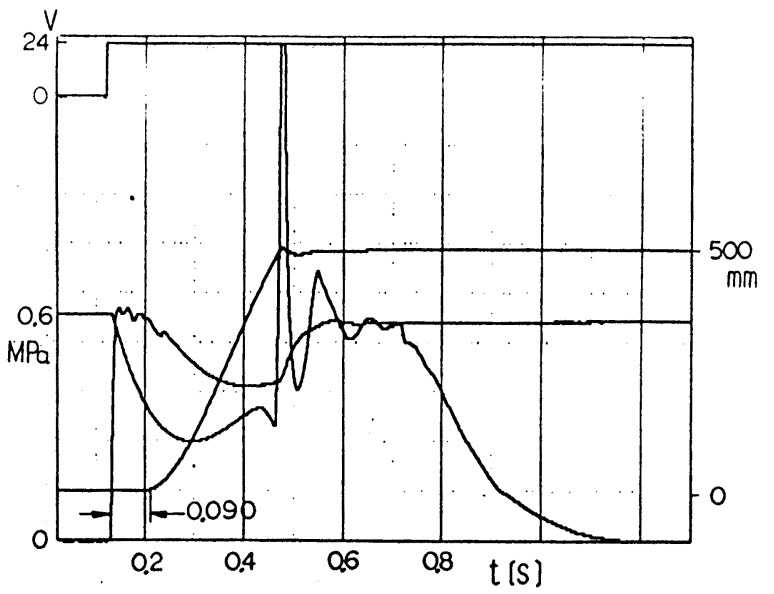

Fig 10 driven with single solenoid

$5 / 2$ valve 